Mariz, R.N., Galvao, E.L., Picchi, F.A., Melo, R.S.S, and Borges, M.C.B. (2019). "Daily Management Application in a Dam Construction Project." In: Proc. $27^{\text {th }}$ Annual Conference of the International. Group for Lean Construction (IGLC), Pasquire C. and Hamzeh F.R. (ed.), Dublin, Ireland, pp. 1425-1434. DOI: https://doi.org/10.24928/2019/0193 Available at: 〈www.iglc.net>.

\title{
DAILY MANAGEMENT APPLICATION IN A DAM CONSTRUCTION PROJECT
}

\author{
Renato N. Mariz ${ }^{1}$, Eduardo L. Galvao ${ }^{2}$, Flavio A. Picchi ${ }^{3}$, Reymard S.S. Melo ${ }^{4}$ and \\ Marcela C.B. Barcelos 5
}

\begin{abstract}
Brazilian construction companies have sought lean thinking to increase competitiveness in the sector. The initial step for lean implementation is to stabilize the project production system. Many lean tools have been applied to stabilize production, however daily managemet is a lean practice that has been implemented in manufacturing and has little application in the construction. This paper aims to explore daily management in the construction context and evaluate the results of its implementation. Action research was the research method adopted. The research lasted three months and was conducted in three stages: the first for preparation, the second for the implementation cycles and the final for analysis and conclusions. The application evaluated the four fundamental elements of daily management: visual management, teamwork problem solving, help chain, and leadership. Daily management implementation facilitated decision-making and problems were solved more often and in a more structured way with the help chain. Visual boards helped the managers to see the production and productivity deviations. Meeting routines provided a more present leadership in the field and a spirit of team collaboration. The main results of the research were the reduction of project costs, project completion on time and increased project team commitment.
\end{abstract}

\section{KEYWORDS}

Daily management, daily huddle, visual management, action learning/research.

\section{INTRODUCTION}

Brazilian construction sector has been facing a crisis that led to a decrease in the number of construction projects. Within this scenario, construction companies further reduced their profit margins to close new contracts (Boshi and Pinho 2018). In a competitive market,

$1 \quad \mathrm{PhD}$ student, Construction Management Research Laboratory (LAGERCON); University of Campinas (UNICAMP) and lean consultant, Lean Institute Brazil; rmariz@lean.org.br

2 Ms.C, University of Campinas (UNICAMP) and lean consultant, Lean Institute Brazil; elavocat@lean.org.br

3 Associated Professor, Construction Management Research Laboratory (LAGERCON); Department of Architecture and Building, School of Civil Engineering, Architecture and Urban Design; University of Campinas, Brazil (UNICAMP), and President, Lean Institute Brazil; fpicchi@ @ean.org.br

4 Assistant Professor, Civil Engineering Dept., Federal University of Rio Grande do Norte, Natal, RN, Brazil, smelo@ct.ufrn.br

$5 \quad$ Planning engineer, Construtora Ápia, MG, Brazil marcela.borges@grupoapia.com.br 
construction companies have sought ways to reduce their costs, such as investments in technologies, building systems and management methods (Tiwari et al. 2018).

Lean Thinking has been an alternative used to increase the competitiveness of companies due to the fact that it is based on eliminating waste along the value stream, thereby shortening lead times, reducing costs and also increasing product quality. (Womack and Jones 2003).

A basic premise for implementing lean is to achieve basic process stability (Ohno 1997). Some tools have been used to achieve basic stability in the construction environment, such as: value stream mapping (VSM), workplace organization (5S Method), Total Productive Maintenance (TPM), Last Planner System and Kanban (Gallardo et al. 2014).

Daily management is a lean practice widely used in manufacturing sector to remove process instability (Liker and Hoseus 2008). In the construction sector there is still no consolidated application of this practice. Therefore, this paper aims to explore the daily management in the construction context and evaluate the results of its implementation.

\section{DAILY MANAGEMENT}

Daily management (DM) is a continuous process that ensures that work is done in the right way and in the right time, in order to achieve business success according to the company's strategic objectives (Ferro and Gouveia, 2015). The Daily Management elements are (Liker and Hoseus 2008; Ferro and Gouveia 2015):

- Visual management: Visualization must be simple in order to ensure clarity and focus, and to allow everybody to understand. A simple board is used to expose targets and problems

- $\quad$ Teamwork problem solving: It's necessary to create an environment in which hiding problems is neither acceptable nor possible. The right way to work, which lean thinking advocates for, is exposing problems, effectively solving them, and asking for help. Just having the numbers exposed is not enough: daily management encourages (and, really, calls for) teamwork and cooperation. The team should always engage in open discussions to understand the situation, do some analysis on the spot, and decide what actions are needed in the event of a gap between current and expected performance.

- Help chain: Essentially, the help chain turns the traditional organizational pyramid upside down, which allows the organization to move away from a command-andcontrol attitude and towards a culture in which all necessary support is given to the processes of value creation and problem solving

- $\quad$ Leadership: Just having the standup meetings is not sufficient. Leadership should be involved every step of the way. They must be capable of keeping the meetings focused and all team members involved. The meeting routines generate great opportunities to develop the employees' capabilities and change they way people tackle problems and work in teams.

The Last Planner System added the daily huddle in an update made by Ballard (2003), but has not been universally practiced (Ballard et al. 2009; Daniel et al., 2015).

Daily huddle focuses on achieving weekly planning for daily control through quick meetings with team members (Ballard et al. 2009). Daily management focuses on solving 
problems through a structured help chain with active leadership participation as a way to develop the team (Ferro and Gouveia. 2015).

\section{RESEARCH METHOD}

The research strategy adopted was action research, which according to Thiollent (2007) is a type of empirical social research that is conceived and carried out in close association with an action or with the resolution of a collective problem and in which researchers and representatives of the situation or problem are involved in a cooperative or participatory manner.

The research was divided into 3 stages. In the first stage a preparation was carried out to understand the main problems of the project and to align the scope of the research. In the second stage, 3 learning cycles were carried out for three months ( 1 month per cycle), where one week a month practical workshops were held in the field with significant collaboration between the researchers and the project team.

In cycle 1 the meeting routines (with the supervisors and their teams) and the visual management were created and implemented. During cycle 2 the meeting routines with the engineers and managers were implemented. The last cycle served to improve the routines, and visual management.

In the third stage a final reflection was made aiming at consolidating this practice in the company and expanding to other projects of the construction company (Figure 1).

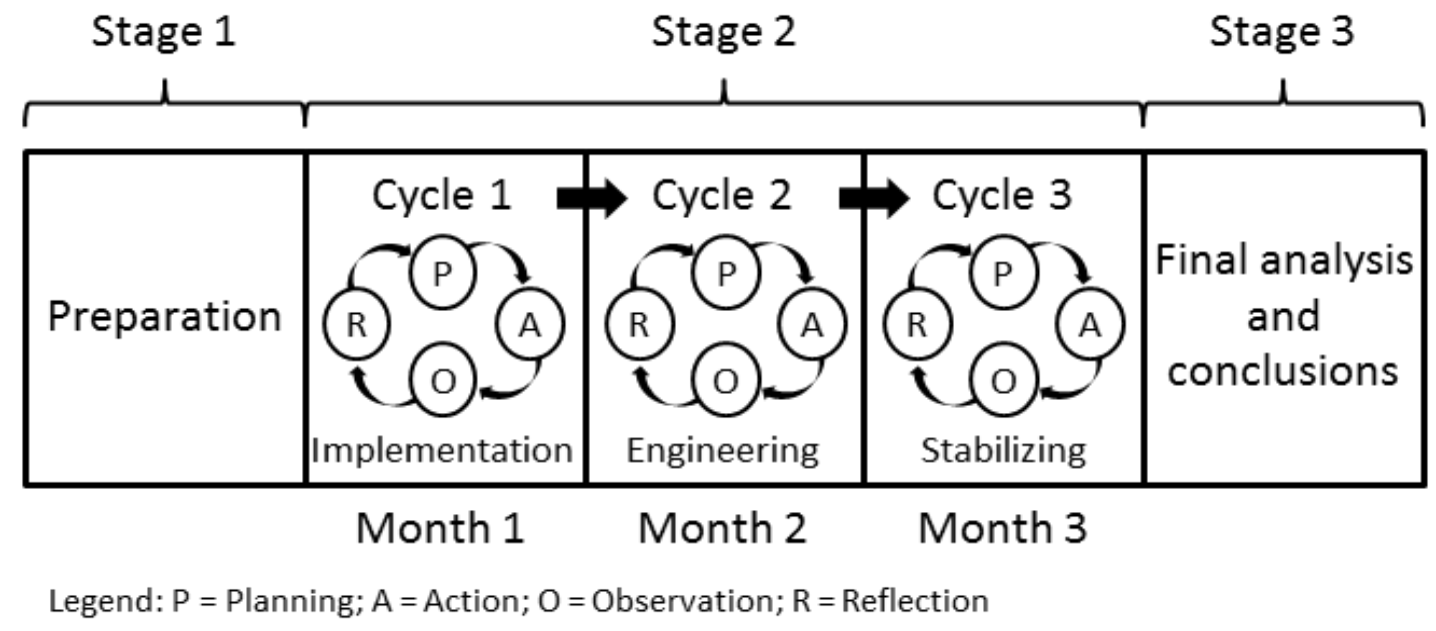

Figure 1: Research Design

The construction company in which this study was developed has almost 60 years of experience in the market and predominantly works with infrastructure projects: paving, dams, drainage, railway, bridges and tunnels.

The pilot project that was chosen by the company was the raising a tailings dam from the $229.60 \mathrm{~m}$ quota to the $245.00 \mathrm{~m}$ quota. This project was divided basically on two tasks: 
A. Materials Sieving Process: part of the material that was released in the dam was sieved to be later taken to the dam, that is, a task was focused in the sieving process (Thick Shale, Fine Shale and Quartz);

B. Dam: Another task was located at the launch of the processed and unprocessed material (clay and filter).

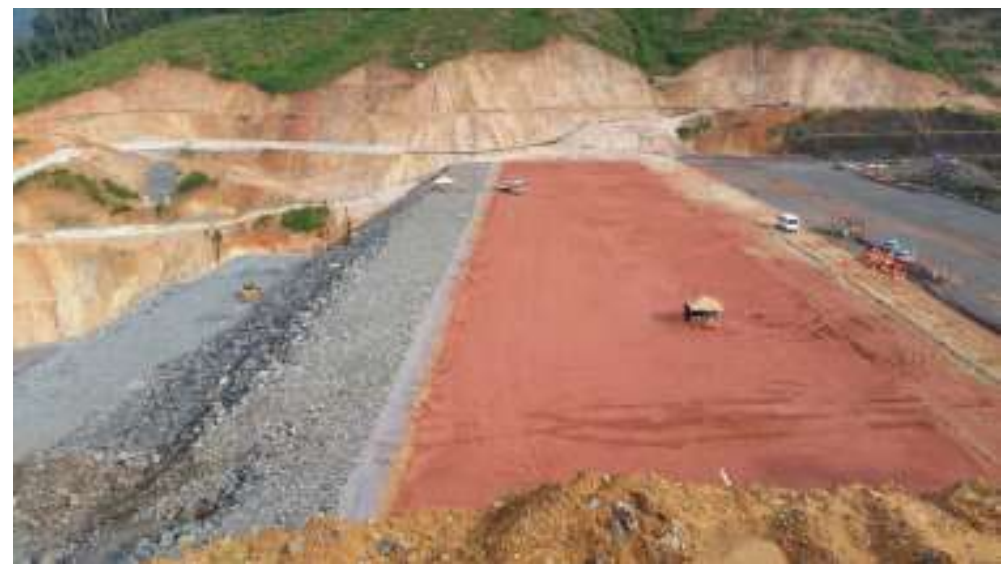

Figure 2: Dam Construction Site

\section{RESULTS AND DISCUSSION}

The discussion and presentation of the results was divided by the elements of daily management, as follows:

\section{VISUAL MANAGEMENT}

Site observations were performed in order to identify some waste. These observations helped the project team to identify that the production process of the tasks (Materials Sieving Process and Dam) was very unstable. At the end of the first week a lecture was given on Daily Management with the lean committee (site manager, planning engineer and lean coodinator). Then, a visual management board (first version) was drawn for the Materials Processing task.

Based on what was already usual and also aligned with the field language, it was decided to use the unit to measure production as "trips" and to measure "trips / trucks" productivity. Finally, a meeting was held with those in charge of the Materials Processing task to explain the new practice, to define schedules and participants in the meeting (Figure 3). 


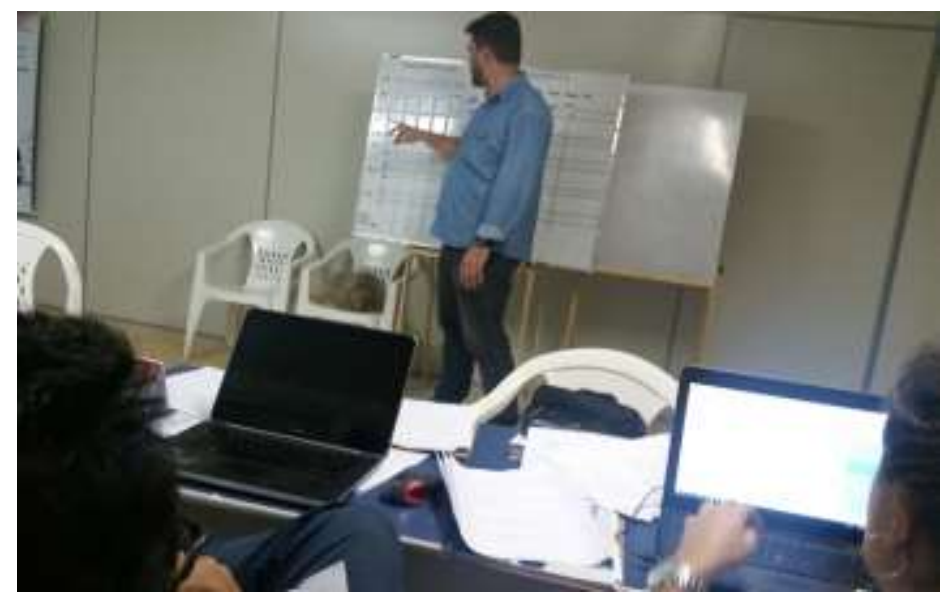

Figure 3: Presentation meeting of the first version of the Daily Management Board

Daily meetings were implemented and consolidated in Materials Sieving Process task in 2 weeks (Figure 4). Supervisors showed resistance to change in the beginning. However, once meeting routine was established they perceived its benefits. Then, daily management was also incorporated in Dam task with some adaptations in the board.

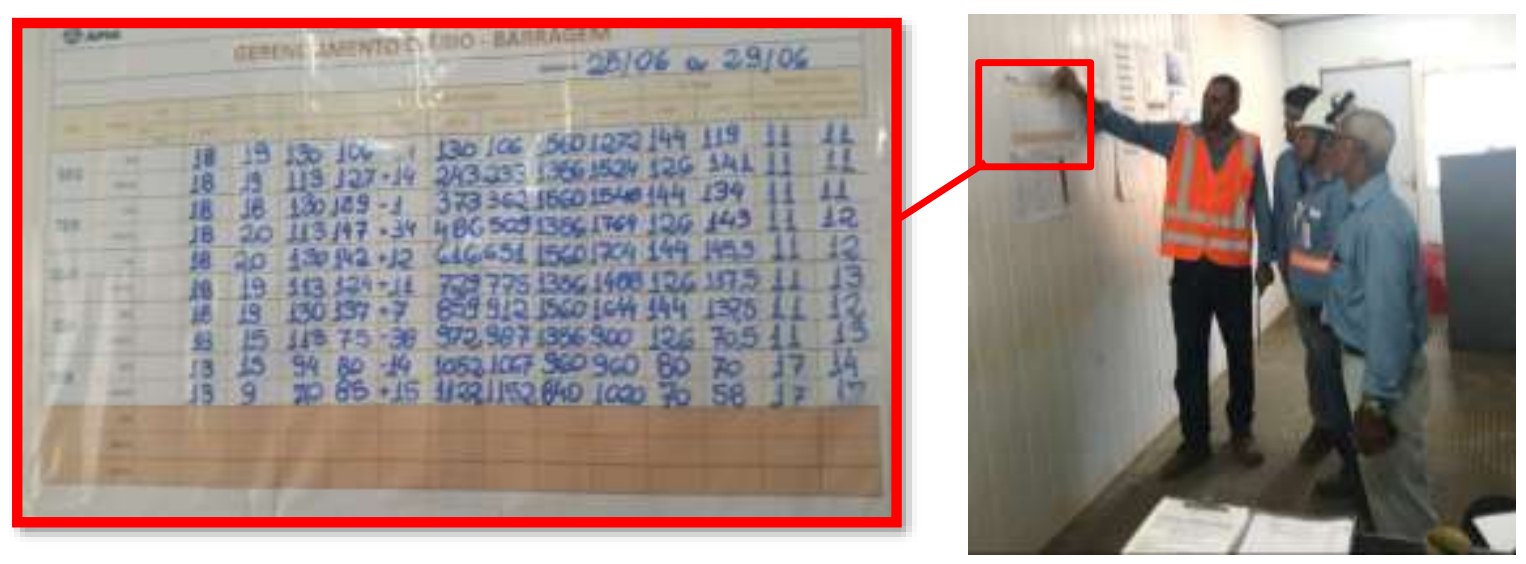

Figure 4: Daily meeting in the dam task

Visual management helped to expose the problems and especially the practical understanding of the concept of production and productivity. Before daily management application, only production was controlled, that is, no matter how many trucks, the goal was always to beat the daily goal of trips.

After the visual management board and the routine of meetings were implemented, the team members began to optimize the use of trucks, including a few times a day to stop trucks from queuing in the cycle when there was a change of schedule.

It is important to note that the trucks were rented and paid per hour used, therefore when queuing occurred in a given cycle and they were connected they would have the cost of rent and diesel. 


\section{TEAMWORK PROBLEM SOLVING}

Team involvement was a key factor in deploying daily management. Many problems were reported with the daily meeting routine implemented. Simple problems were solved with immediate team action and larger problems needed further analysis with the engineering team. During the first month some recurring problems were identified. The most recurring problem for material sieving process was the instabilities in the truck cycles, while for the dam task was the number of trucks above planned.Problems were understood in their root causes with the help of the engineering team. It was identified that the constant change in the location from which the processed material would be withdrawn and transported to the dam caused problems in production in relation to the amount of trucks and machines that would be used to do this task.

Some truck queues could be seen when walking by the field. Every day the client gave information shortly before starting the working day or other times after starting from which stock should be removed the material to be released to the dam. The change was due to the fact that an inventory of benefited material could only be released to be transported once it was fully stocked and the topography team raised its volume.

The team then proposed as a countermeasure the creation of a worksheet that mapped all the possible scenarios and that could absorb the daily changes made by the client. Therefore, all inventories and ATDs (Average Transport Distance) were obtained with revised and timed data in gemba.

This worksheet has been distributed to all team members. Then, they started to have more autonomy in the field and also started to control the correct amount of trucks. A visual board was also created as a way to identify daily from where the materials were being removed (Figure 5).

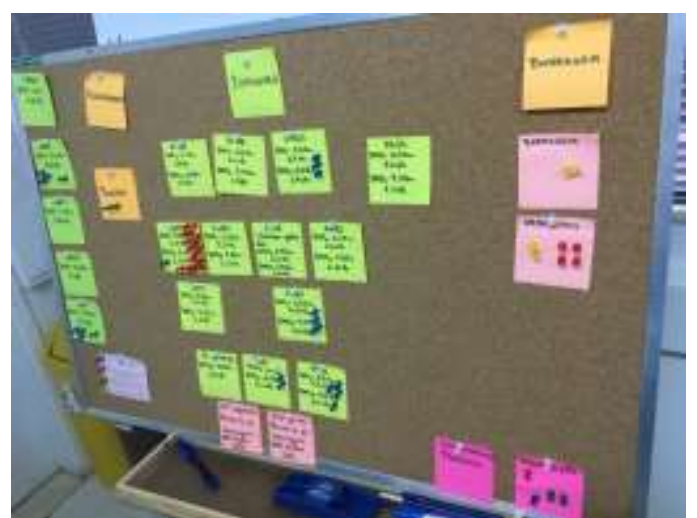

Figure 5: Visual Control of inventories, trucks and machines

\section{HELP CHAIN}

The help chain worked informally, that is, actions were taken on some problems that came from the field, however there was no priority, control or follow-up actions. The contract manager and planning engineer himself missed some of the field information more often.

Then, in the second month when the daily field meetings were already going as planned, the engineering team decided to hold a quick meeting $(15-30 \mathrm{~min})$ at 11:30 a.m. so that they 
could align the field information daily, discussing them, generating actions and monitoring them.

Some problems that were staggered from the field meeting to the engineering meeting were already solved by immediate action, while other actions would require visual management for follow-up, so the team deployed a "Kanban" board (Figure 4). Therefore, a structured help chain with field and engineering participation was established (Figure 6):

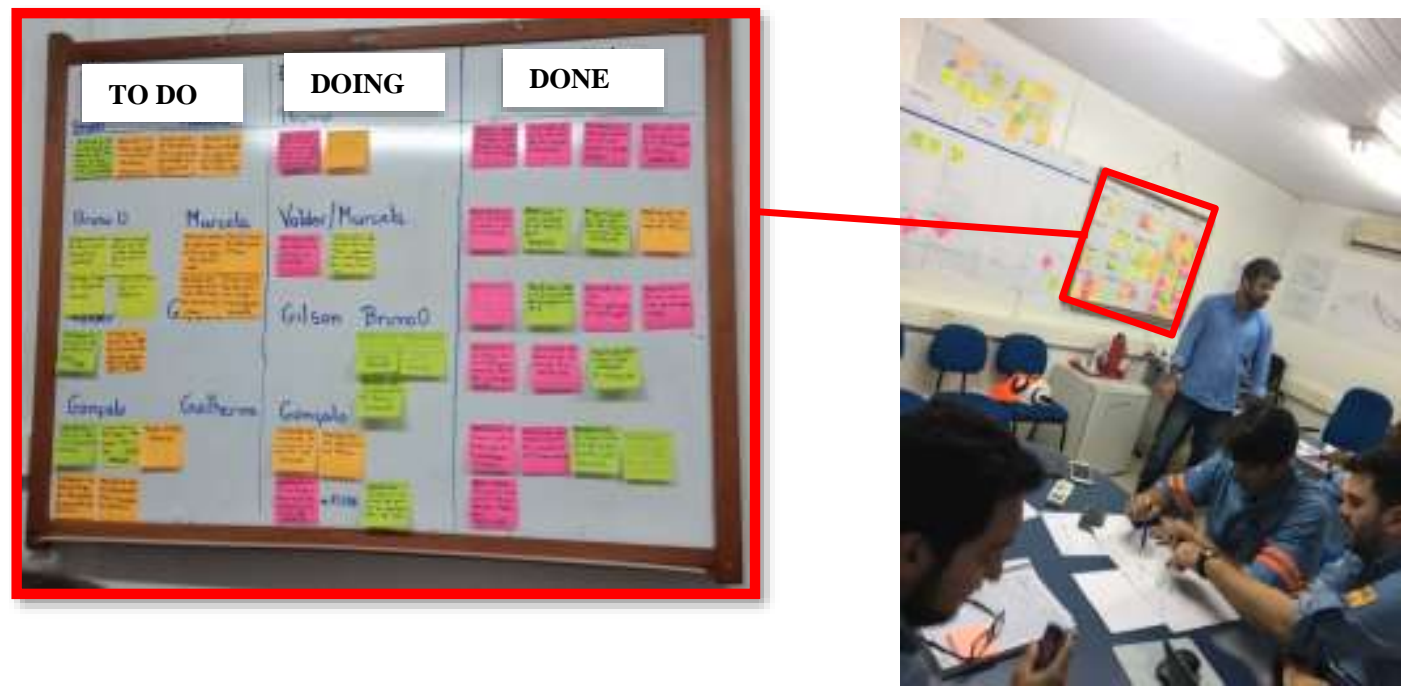

Figure 6: Engineering daily management utilizing the "Kanban" board

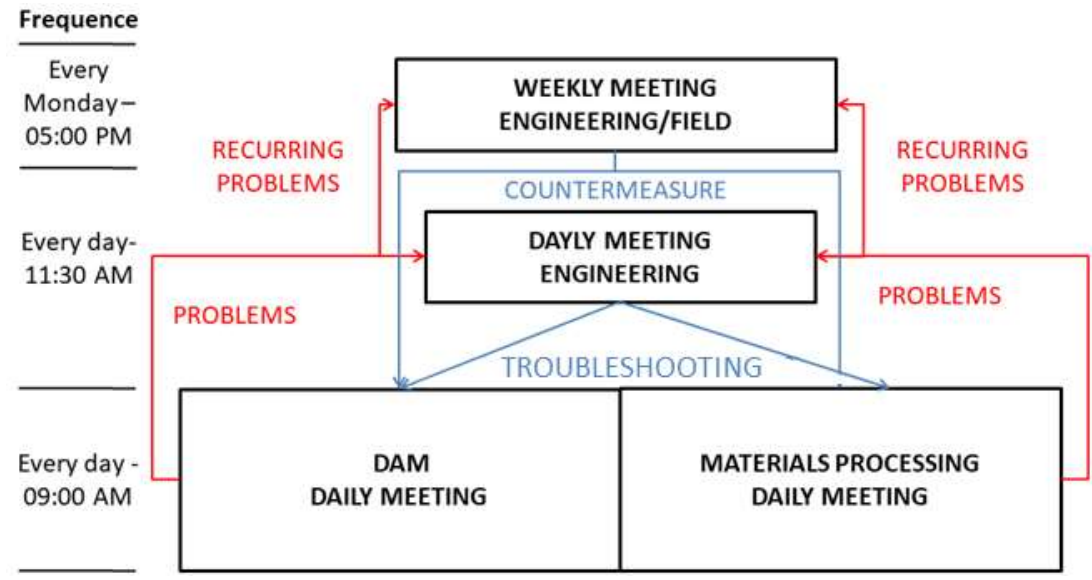

Figure 7: Help Chain

\section{LEADERSHIP}

The role of leadership was fundamental in implementing daily management. The change of mindset in particular from the engineering team was felt by the project team. The planning engineer and the project manager who did not go often to gemba started to go frequently, since a rotation of participation in the meetings involving (project manager, lean manager and planning engineer) was established, therefore, at least 3 times per week 
they attended the daily meeting in the field, in addition to attending the engineering meeting every day.

As time went by, the team members brought more problems and more actively participated in the meetings. They reported the importance of the presence of the engineers and especially of the actions that were taken at the meetings with their help.

\section{GENERAL RESULTS}

The last project had cost overruns of $30 \%$ leading the company to implement the aforementioned lean practices to make a turnaround in this scenario. After the end of the project, some data were collected and the cost reduction became evident:

- $\quad$ Materials Processing task - 4\% reduction in cost (US\$71.200,00)

- $\quad$ Dam task - 7\% reduction in cost (US\$ 535.000,00)

This result came especially from the reduction of the planned quantity of trucks (representing $70 \%$ of the project cost) and the best use of the trucks that were available.

Transparency through visual management was also positive for the team. This made the data simple and easy to be controled by the team members.

Furthermore, the project was completed within planned schedule and it was noticed the change of behavior of the managers and engineers who focused not only on production but also on productivity. Such a concept helped to always be aware of the waste and daily problems.

\section{CONCLUSION}

Daily management implementation enabled the team to identify deviations daily in production, causing them to take immediate action to correct them.

Visual management helped to clarify the production and productivity goals of the dam and materials processing tasks team. The information on the board served as the meeting's north, including to point out deviations.

Team involvement in problem solving made it easier to identify problems and take action. Team involvement also helped to improve the sizing of the truck cycle.

Help chain alongside with field meetings and engineering team meetings helped to solve more complex problems, as engineering team began to make decisions based on the information that came from the field every day, including monitoring the actions that should be taken.

Leadership has become more present and participatory in gemba. The field team's own perception of the actual presence of engineering team was noted as positive.

Benefits generated by the daily management implementation went beyond the quantitative sphere (cost and time) and were also qualitative (increased transparency and behavior change).

Daily support of these practices helps the company stabilize its processes and also promote improvements. The daily management was considered a fundamental practice for 
the construction company that will take advantage of the learning of this project to expand this practice to other projects of the company.

Future research might explore daily management system in other company departments (supply, work safety, and quality). A further study could involve the top management level on daily problem solving.

\section{AKNOWLEDGEMENTS}

Authors would like to thank CAPES for funding part of the study.

\section{REFERENCES}

Ballard, G. and Howell,G.A,. (2003). An Update on Last Planner. In: Proc. 11th Ann. Conf. of the Int'l. Group for Lean Construction. Virginia.

Ballard, G., Hammond, J. and Nickerson, R. (2009). Production Control Principles. In:, Proc 17th Ann. Conf. of the Int'l. Group for Lean Construction. Taipei, Taiwan, pp 489-500.

Boshi, R., and Pinho,C. (2018)." Crisis and austerity: the recent trajectory of capitalist development in Brazil." Contemporary Politics.,28(1-22).

Daniel, E.I., Pasquire, C. and Dickens, G., (2015). Exploring the implementation of the Last Planner® System through IGLC community: twenty one years of experience. In: Proc. 23rd Ann. Conf. of the Int'l. Group for Lean Construction. Perth, Australia

Ferro, J., and Gouveia,R. (2015). How to create an effective daily management system. Planet Lean.

Gallardo, C., Granja., A., and Picchi,F. (2014). "Productivity Gains in a Line Flow Precast Concrete Process after a Basic Stability Effort". ASCE, J. Constr. Eng. Manage., 140(4).

Liker, J.K. and Hoseus, M. (2008). Toyota Culture McGraw-Hill: New York, NY. 562pp

Ohno, T. (1988) Toyota Production System; Beyond large scale production, Productivity Press, Portland, Oregon.

Thiollent, M. (2011): Action Research Methodology. 18.ed. São Paulo: Cortez, 2011.

Tiwari,S., Chan, S., and Mubarak,M. (2018). Critical analysis of procurement techniques in construction management sectors. IOP Conf. Series: Materials Science and Engineering 342.

Womack, J.P., and Jones, D.T (2003) Lean Thinking. Revised and updated. Free Press. 
Mariz, R.N., Galvao, E.L., Picchi, F.A., Melo, R.S.S, and Borges, M.C.B 